\title{
Personalized Goals for Positive Behavioral Support: Engaging Directly with Children who have Intellectual and Developmental Disabilities
}

\author{
Nick James Gore $\mathbb{D}^{1} \cdot$ Peter McGill ${ }^{1} \cdot$ Richard Patrick Hastings ${ }^{2,3}$
}

Accepted: 23 November 2020 / Published online: 5 January 2021

(c) The Author(s) 2021

\begin{abstract}
Stakeholder involvement is fundamental to Positive Behavioral Support yet research in this area rarely obtains views of children with Intellectual and Developmental Disabilities. This study aimed to develop and demonstrate a means of engaging directly with children to identify personalized goals and priorities for their future support. An augmented communication approach was used to facilitate interviews with children who had a range of disabilities and displayed behavior that challenges. The interviewer asked children about activities, their own behavior, a caregiver's behavior, and quality of life to focus future potential assessment and intervention. We completed interviews in at least some areas with 9 out of 14 children. Children prioritized goals for future support and evidenced insight into behavior, needs, and preferences. These findings have promising implications for further direct engagement of children with disabilities throughout a support pathway to achieve outcomes rich in social validity.
\end{abstract}

Keywords Positive Behavioral Support $\cdot$ Children $\cdot$ Goals $\cdot$ Engagement $\cdot$ Communication

\section{Highlights}

- This study interviewed children with Intellectual and Developmental Disability about their goals and priorities for support.

- An augmentative communication approach (Talking Mats) was used.

- Children who completed interviews identified goals and priorities for their behavior, caregivers and other life areas.

- It is possible to engage directly with some children who have intellectual and developmental disabilities in behavior support research and practice.

Children with Intellectual and Developmental Disabilities (IDD) typically present with a range of difficulties concerning communication and adaptive skills; often experience physical health problems and encounter psychosocial

$\triangle$ Nick James Gore

N.J.Gore@kent.ac.uk

1 Tizard Centre, University of Kent, Cornwallis NE, Canterbury, Kent CT2 7NF, UK

2 CEDAR Centre, University of Warwick, Room WE139, New Education Building, Westwood Campus, Coventry CV4 7AL, UK

3 Department of Psychiatry, Centre for Developmental Psychiatry and Psychology, School of Clinical Sciences at Monash Health, Monash University, Melbourne, VIC, Australia adversity, all of which places them at increased risk of behaviors that challenge $(\mathrm{CB})$ relative to their peers (Gore et al. 2014; McClintock et al. 2003; Totsika et al. 2011a, b). Positive Behavioral Support (PBS) incorporates and builds upon the concepts and applications of behavioral science (Baer, Wolf and Risley 1968), human rights and valuesbased approaches to provide a framework of evidence-based practice for those at risk of CB (Carr et al. 2002; Gore et al. 2013; Horner et al. 1990; Kincaid et al. 2016). PBS recognizes that $\mathrm{CB}$ develop within the context of biological and psychosocial aspects of disability and via interactions between an individual, people around them and their environment to serve important functions (Hastings et al. 2013).

Based on this understanding, PBS seeks to enhance skills, opportunities, environments and interactions in ways related to an individual's specific needs and aspirations and 
reduce risk of $\mathrm{CB}$ over both the short and longer term. Development of socially and personally valued adaptive behaviors and improvements in life quality in addition to changes in $\mathrm{CB}$, should therefore be both a focus of outcomes in PBS and the means through which desired outcomes are brought about, (Carr 2007). Committing to and demonstrating the full breadth of approaches and values integral to PBS in this way remains, however, a challenge for the field (Clarke and Dunlap 2008; Kincaid et al. 2002). Maximizing opportunities for people with IDD themselves to determine the focus of behavioral support may be one key way in which the values of PBS can be better actualized in practice. Building on more general calls to address, what are frequently, missing voices in IDD research (Farrell and Krahn 2014), this study therefore aimed to develop and explore a goal-selection procedure for direct use with children who have IDD and are in need of behavioral support.

Person-centered planning (Kincaid and Fox 2002) and stakeholder involvement (Lucyshyn et al. 2007; McLaughlin et al. 2012) are considered fundamental to supporting the kind of socially-valid outcomes and practices that PBS demands (Dunlap 2006). These approaches have relevance throughout a pathway of support but are perhaps most critical during early planning stages to identify goals that are grounded in the strengths, hopes and concerns of all involved (Dunlap and Fox 2007), and give direction to future assessment and intervention that may follow. In the case of children, person-centered activities and other PBS procedures should typically involve engagement with family caregivers and professionals who know the child well and whose own behavior may require support as part of a multi-component plan (Gore et al. 2013). These practices tend to be highly valued by families, and have been the recent focus of related research in this journal (i.e., Gore et al. 2019). Children with IDD themselves are however, very seldom consulted directly within a PBS pathway (Kruger and Northway 2019; Wehmeyer et al. 2004) and little behavioral technology has developed to support their inclusion in this way, with two possible exceptions.

First, preference assessments are well established in the field of Applied Behavior Analysis (Virués-Ortega et al. 2014) and are often used within PBS to identify reinforcing stimuli. Here, views of other informants do not always correspond to an individual's observed preferences regarding functional reinforcers (Green et al. 1988; Parsons and Reid 1990), underlining the fundamental importance of direct engagement with the focal person during such procedures. Secondly, some attempts have been made to advance student-directed functional assessments, where both convergence (Kinch et al. 2001; Reed et al. 1997; Wehmeyer et al. 2004) and divergence (Murdock et al. 2005; Stage et al. 2006) between responses of students and other informants have been reported. Whilst demonstrations of student engagement, these functional assessment procedures have largely used verbal communication methods alone and been utilized primarily with children with minimal/no degree of intellectual disability. In addition, and fundamentally, both preference assessments and functional assessments have a different focus and scope to goal selection and so represent necessary but incomplete opportunities for children with IDD to shape their own behavior support.

Outside of PBS, several attempts have been made to gain perspectives of children with varying levels of intellectual disability and/or autism. This includes studies relating to evaluations and indicators of service quality (Aston et al. 2014; Boyden et al. 2012; Mitchell and Sloper 2001, 2003; Preece and Jordan 2010) with at least some examples and guidance available to support interviews with children with significant communication difficulties (Bedoin and Scelles 2015; Mitchell and Sloper 2011). We could find only one study on children's perspectives (Boyden et al. 2012) with a connection to their CB. Boyden et al.'s service evaluation included interviews with children with a history of $\mathrm{CB}$, following input from a mental health service. Further to this, a study by Byrne and Hennessy (2009) explored views of children with IDD in relation to vignettes depicting behavior of a fictional peer. Neither of these studies was conducted within the context of personalized goal formation for a child's own/current behavior prior to provision of support.

The PBS framework and related research to date has therefore prompted, but not adequately addressed, ways to support direct engagement with children with IDD as active stakeholders in their own behavioral support. To address this research and practice gap, we utilized an augmentative communication method supportive of low verbal ability to explore the utility of a person-centered goal selection process for children with IDD who displayed CB. We suggest that such an approach could provide a way to help children and young people identify skills, needs and aspirations and highlight areas of both dissatisfaction and importance for their own life; information that may be of critical importance to structure effective support arrangements (e.g., scheduling of activities) and guide future functional assessment and behavior support planning processes. The study had two aims: (1) to develop and test the utility of a goal selection procedure of this nature, and (2) to describe goals and priorities expressed by children and explore processes involved in the identification of these.

Interviews were facilitated using Talking Mats (TMs), a versatile and structured, visually-based communication tool that enables people to organize and express their views (Murphy and Cameron 2008). Whilst other augmentative approaches exist, and may also be helpful in engaging children with IDD (Romski et al. 2015), TMs appeared a particularly promising starting point for exploring children's priorities and goals in the current study. From a research perspective, TMs have previously been used to 
Table 1 Participant characteristics

\begin{tabular}{lcllll}
\hline Name & Age (years) & Sex & Diagnoses & Communication & Behavior that challenges \\
\hline Billy & 5 & Male & ${ }^{a}$ ASC & Verbal & TA; NC \\
Laura & 9 & Female & Pathological Demand Avoidance; ASC & Verbal & VBC; PA; SI; DP; TA; NC \\
Natasha & 12 & Female & Moderate aID; Reactive Attachment Disorder & Verbal & VBC; PA; SI; DP \\
Edward & 9 & Male & Down Syndrome; Severe ID & Limited verbal; Makaton & VBC; PA. \\
Stephen & 10 & Male & Down Syndrome; ID; ASC & Limited verbal; Makaton & VBC; PA; SI \\
Peter & 15 & Male & ASC; Severe ID & Verbal & PA; SI; DP \\
Emily & 10 & Female & ASC; ID; Fetal Valproate Syndrome & Verbal & VBC; PA; TA \\
Max & 10 & Male & ASC; ID; Fetal Valproate Syndrome & Verbal & PA; TA \\
Scot & 8 & Male & Cri de Chat Syndrome; ID & Non-verbal; PECS & SI \\
David & 9 & Male & ASC & Verbal & VBC; PA; DP; TA \\
Ben & 10 & Male & ASC & Verbal & VBC; PA; SI; TA. \\
Richard & 5 & Male & ASC; ID & Non-verbal; PECS & VBC; PA; SI; TA \\
Alison & 4 & Female & ASC; Global Developmental Delay & Non-verbal; PECS; gestures & PA; NC \\
Joseph & 10 & Male & ASC; Severe ID & Limited verbal; Makaton & VBC; PA; SI; \\
\hline
\end{tabular}

${ }^{a} A S C$ Autism spectrum condition, $I D$ intellectual disability, $T A$ tantrum or angry and upset, $N C$ non-compliance, $V B C$ verbal behaviors that challenge, $P A$ physical aggression, $S I$ self-injury, $D P$ damage to property

good effect in studies ascertaining views of children with IDD (without $\mathrm{CB}$ ) regarding a range of topics (Mitchell and Sloper 2001; Small et al. 2013). From a pragmatic and clinical perspective, TMs also have strengths in that they can be used to support people with even low levels of receptive communication ability (those with two-word receptive understanding); are low cost and can be used without the need for extensive prior training with children.

\section{Method}

\section{Participants}

This study recruited children and young people who had a diagnosed IDD that related to multiple domains of need and who were currently exhibiting CB. Criteria for recruitment also required: Families of children and young people to be seeking or awaiting service support in relation to their child's behavior but not yet in receipt of this (thus indicating a high level of need, and providing a timely context for exploring goals for future support); children and young people to have receptive language ability (as estimated by their caregivers) at a two-word level (i.e., able to follow instructions including two information carrying words in context) as required for engagement with the communication method utilized in the study (see below). Participants recruited for the study were 14 children (10 males, 4 females with mean age 9 years, range 4-15 years) with IDD who displayed differing forms of CB. Children's expressive communication abilities varied, with some using largely verbal methods and others utilizing symbol or sign-based systems.

\section{Ethics}

The National Research Ethics Service committee in SouthEast England granted ethical approval for this study. Researchers gained parental consent for the involvement of all participating children and young people and care was taken to check for the child's assent in taking part in the study procedures (see below).

\section{Interview}

Interviews were conducted using a Talking Mats (TM) approach. All TMs consist of a set of symbols relevant to a subject area. Individuals are asked semi-open questions in relation to each symbol and invited to place this on an area of the mat corresponding to their views, feelings, or experiences. Typically, TMs are divided into two columns to indicate items an individual favors or experiences frequently and those they do not like or seldom experience. Depending on communication level, a middle column can be introduced to a TM, allowing interviewees to indicate items they are not sure of, that happen occasionally, or they like to some extent. In all cases, placements are used as a starting point for further communication exchanges (Table 1).

In this study, TMs were used to guide interviews structured around six topics that covered preferred activities, adaptive and challenging aspects of children's own behavior, their caregiver's behavior, and life quality domains. The topic areas related to the breadth of goal areas and intervention approaches conceptually possible within a PBS framework. Interviews aimed to support participants to consider a range of possibilities for their future support and 
to identify areas that were personally meaningful. For instance, we asked children "tell me about asking for help. Is that something you do a lot or something you do not do?" in relation to the adaptive behavior topic. The interviewer then handed the corresponding stimulus card to the child to place on an area of the mat that reflected their thoughts/ perspective. As is a standardized element of the TM approach, at the end of each mat the researcher verified interpretation of a child's responses by feeding back placements that had been made, and checking these corresponded to the child's views. The interviewer allowed each child to change or clarify placements at this time and add any other stimuli of their choosing (blank cards were available as is customary in TM procedures). Additionally, and specifically to this study, following placements and discussion, the interviewer asked children to identify onetwo items they would like support for in the future.

The TM procedure and full range of stimuli for each mat were manualised (available upon request from first author) to ensure a replicable methodology for both clinical and research settings. Table 2 presents all topics and subcategories depicting the number and array of stimuli prepared. Physical/non-electronic TMs were used (a piece of carpet $\sim 40 \times 30 \mathrm{~cm}$ ) with a pre-prepared set of line-drawn symbols. Interview topics were ordered in level of increasing complexity (as indicated) to support children's early engagement. Within session discussions were supported where possible by verbal communication, signing (i.e., Makaton), and gestures.

\section{Procedure}

Preparation sessions (30-50 min) were completed with each participant's caregiver to ask about their child's communication and behavioral needs prior to interviews. These sessions were used to help plan and organize the main goal-selection interviews for children and young people. Following discussion, individualized plans were created for each child to minimize the likelihood of $\mathrm{CB}$ within interviews and manage this safely if it should occur. In all cases, it was agreed interviews would be terminated following any $\mathrm{CB}$ or indication that the child did not assent to continue. Preparation sessions were also completed with children. In half of the cases, this involved a preliminary visit to a child's home or school (30-40 min) during which the researcher engaged in preferred activities with the child. In all other cases, equivalent additional time was built into the start of interview sessions. These sessions allowed the researcher to develop rapport and further gauge participants' communication abilities, as recommended in prior research interviewing children with IDD (Bedoin and Scelles 2015).

The main goal-selection interviews with children were arranged at a time and place convenient to families, and completed within 1-2 sessions of 30 to $60 \mathrm{~min}$. The interviewer proactively offered breaks to children during sessions. In breaks, children completed preferred activities (jointly with the researcher or alone, as preferred by the child). Interviews were typically conducted alone with the child. In a small number of instances, caregivers sat in a different area of the room but were asked not to contribute to the interview. Time with children was limited to two sessions and so interviews were ended at this point even if all mats had not been attempted. Interviews were also ended where the researcher judged remaining mats to be too complex for the child (based on prior responses). Interviews were video-recorded and later transcribed/analyzed in an anonymized form. All participants received an accessible summary report detailing the goals/priorities they had generated within interview that could be used as a starting point for behavior support planning after the study.

\section{Data Analysis}

A TM was considered completed if children were able to make valid placements of stimuli relevant to the given topic area. A discrete-response coding system was devised for the current study to verify the validity of children's responses. Researchers viewed videos of participants one TM at a time.

Table 2 Interview topics and stimuli

\begin{tabular}{lll}
\hline Topic area & TM stimuli & Examples \\
\hline $\begin{array}{l}\text { Things you enjoy (preferred) } \\
\text { Things you do (adaptive) }\end{array}$ & $20(12 \times$ home based activities; $8 \times$ community activities $)$ & Drawing \\
$\begin{array}{l}\text { Other things you do } \\
\text { (challenging) }\end{array}$ & $22(12 \times$ social skills; $5 \times$ daily living; $5 \times$ coping skills $)$ & Sharing \\
$\begin{array}{l}\text { Things your parent does } \\
\text { (positive) }\end{array}$ & $12(3 \times$ social; $6 \times$ joint activities; $3 \times$ support strategies $)$ & Kicking others \\
$\begin{array}{l}\text { Other things your parent does } \\
\text { (unhelpful) }\end{array}$ & $\begin{array}{l}12(3 \times \text { positive punishment strategies; } 6 \times \text { negative punishment strategies; } 3 \times \\
\text { other })\end{array}$ & Helping you \\
$\begin{array}{l}\text { Things that are important (life } \\
\text { quality) }\end{array}$ & $\begin{array}{l}8(\text { community engagement; physical health, emotional health; relationships; self- } \\
\text { determination; personal development; material; rights })\end{array}$ & Relationships with others \\
\hline
\end{tabular}


Placements were recorded for each stimulus presented and a confidence rating of high or low was then made based on an estimation of the validity of the child's response. The observed position of stimuli on a mat following a participant's response was used to code placements (i.e., the area/ column depicting stimuli that was favored/experienced frequently, or not liked/seldom experienced, or partially liked/ experienced). Low confidence ratings were made if placements appeared motivated by acquiescence; were contrary to other communications (e.g., the child said "don't like" and placed the item in the highly preferred column); where the child was highly distracted (e.g., placement appeared nonintentional), or where placements appeared motivated by a sensory stimulation function (e.g., lining items up to create a visually reinforcing display). High confidence was assumed and rated in the absence of these low confidence indicators.

A second observer viewed videos from a randomly selected $50 \%$ of participants, in each case coding at least $50 \%$ of TMs from the interview and covering all categories of TM from the study overall. Inter-rater reliability (based on both placements and confidence ratings) was $100 \%$ (total agreements divided by total agreements plus total disagreements $\times 100$ ). In addition, the second observer (a TM trainer), completed the Effectiveness Framework of Functional Communication (EFFC) (Murphy and Camerson 2008) for each mat in their sample. This tool is commonly used in TM research and provides 7, 0-4-point ratings concerning quality of communicative interactions based on the behavior of both the speaker (child) and listener (researcher). A score of 21 out of 28 represents effective TM communication. Average EFFC ratings for TMs were 27.7 (range 25-28, with all but one TM scoring 28).

In addition to stimuli placements, researchers recorded any explicit goals children made at the end of each TM (goal formation was not taken as an indicator of TM completion since a child may or may not have prioritized a goal in that area) and noted verbal responses that were later transcribed. The first author reviewed transcripts in detail and analyzed these using a thematic approach (Braun and Clarke 2006) in relation to each mat, across all children. Transcriptions were analyzed alongside stimuli placement records to support an integration of both data sources and help further explore the manner in which children used the mat and perceived the topic area.

\section{Results}

We could interview 9 of the 14 children (64\%), with some variation in the mats completed on each occasion (see Table 3 for a breakdown of each child's responses and Table 4 for an overview of sample responses). Notably, whilst eight of the children completed between four and six TMs, it was only possible to complete one mat with Stephen who did not appear to understand questions attempted in subsequent stages. In all other cases $(n=5)$ a variety of attempts were made to interview children via TMs but an effective strategy could not be identified. All of these children were described as having limited or no verbal communication skills. Attempts included adaptations to the format of TMs and stimuli, extended periods of introducing the approach in relation to concrete topics, and preliminary sorting/selection exercises. In some instances, children were still able to give some apparent indication of preference to presented items but could not express this in a TM interview format. For instance, Edward smiled/laughed at photographs of activities that his caregiver reported he typically enjoyed. He also stated "bad" and screwed up his face when presented with a picture of a doctor. Notably, Edward had recently undertaken several painful operations. Other than Stephen, the majority of children completed between four and six TMs each, with the later TMs (relating to parent behavior and life quality) being completed the least. All children who completed more than one TM also selected goals during the interview (with each child selecting goals for three TMs on average). Across the sample, four to five children selected goals following each TM (with variation as to which children selected goals on each occasion), excepting the final life quality topic where no specific goals were formed by any child. Goals were selected most frequently in relation to children's own CB (by five children).

\section{Things You Like}

All nine children completed a TM relating to preferred activities. The majority (eight) indicated relative preference for activities across three basic column areas. For instance, Laura (Fig. 1) indicated she liked eight activities (including trampolines and going to the cinema), somewhat liked three (swimming, computers and crafts), and did not like four (shopping, sports, numbers, and reading). For Stephen, two column areas were used. Stephen communicated that he enjoyed five activities (gardening, computers, church, TV, and swimming). When positioning activities to indicate high preference, children referenced both liking and/or being skilled at the activity and three of the children also gave a rationale for placing items in the middle column that either discriminated particular aspects of the activity or highlighted conditions that determined whether it was enjoyed (square brackets indicate the item being discussed):

'[Scooter] Yes I'm really good at that' (Emily)

'If food shopping down here.' 'Toy shopping! Then down here.' (Laura) 
Table 3 Topic areas completed in each participant interview

\begin{tabular}{|c|c|c|c|c|c|c|}
\hline \multirow[t]{2}{*}{ Participant } & \multicolumn{6}{|c|}{ Topic areas } \\
\hline & $\begin{array}{l}\text { Preferred } \\
\text { activities }\end{array}$ & $\begin{array}{l}\text { Adaptive } \\
\text { behavior }\end{array}$ & $\begin{array}{l}\text { Behaviors that } \\
\text { challenge }\end{array}$ & $\begin{array}{l}\text { Caregiver } \\
\text { positive }\end{array}$ & $\begin{array}{l}\text { Caregiver } \\
\text { unhelpful }\end{array}$ & $\begin{array}{l}\text { Life } \\
\text { quality }\end{array}$ \\
\hline Billy & $\mathrm{Yes}^{\mathrm{a}}$ & Yes & Yes & Yes & Yes & No \\
\hline Laura & Yes & Yes & Yes $^{\mathrm{a}}$ & $\mathrm{Yes}^{\mathrm{a}}$ & $\mathrm{Yes}^{\mathrm{a}}$ & Yes \\
\hline Natasha & $\mathrm{Yes}^{\mathrm{a}}$ & Yes $^{\mathrm{a}}$ & Yes $^{\mathrm{a}}$ & Yes & $\mathrm{Yes}^{\mathrm{a}}$ & Yes \\
\hline Stephen & Yes & No & No & No & No & No \\
\hline Peter & $\mathrm{Yes}^{\mathrm{a}}$ & $\mathrm{Yes}^{\mathrm{a}}$ & $\mathrm{Yes}^{\mathrm{a}}$ & $\mathrm{Yes}^{\mathrm{a}}$ & Yes & No \\
\hline Emily & Yes & Yes & Yes & Yes & No & Yes \\
\hline Max & $\mathrm{Yes}^{\mathrm{a}}$ & Yes & Yes & $\mathrm{Yes}^{\mathrm{a}}$ & No & No \\
\hline David & Yes & $\mathrm{Yes}^{\mathrm{a}}$ & $\mathrm{Yes}^{\mathrm{a}}$ & Yes & $\mathrm{Yes}^{\mathrm{a}}$ & No \\
\hline Ben & Yes & $\mathrm{Yes}^{\mathrm{a}}$ & Yes $^{\mathrm{a}}$ & Yes $^{\mathrm{a}}$ & $\mathrm{Yes}^{\mathrm{a}}$ & Yes \\
\hline
\end{tabular}

${ }^{\mathrm{a}}$ Selected goal on this TM

Table 4 Mats completed and goals selected

\begin{tabular}{|c|c|c|c|c|}
\hline \multirow[t]{2}{*}{ Topic area } & \multicolumn{2}{|l|}{ Talking mat } & \multicolumn{2}{|l|}{ Goals } \\
\hline & Completed & Age (years) and sex & Selected goal & Age (years) and sex \\
\hline Preferred activities & $n=9(100 \%)^{\mathrm{a}}$ & $M: 10(5-15)(3 \times$ females $)$ & $n=4(44 \%)$ & $M: 11(5-15)(1 \times$ female $)$ \\
\hline Adaptive behavior & $n=8(89 \%)$ & $M: 10(5-15)(3 \times$ females $)$ & $n=4(44 \%)$ & M: $12(9-15)(1 \times$ female $)$ \\
\hline Behaviors that challenge & $n=8(89 \%)$ & $M: 10(5-15)(3 \times$ females $)$ & $n=5(56 \%)$ & M: 11 (9-15) $(2 \times$ female $)$ \\
\hline Caregiver positive & $n=8(89 \%)$ & M: 10 (5-5) $(3 \times$ females $)$ & $n=4(44 \%)$ & M: $11(9-15)(1 \times$ female $)$ \\
\hline Caregiver unhelpful & $n=6(67 \%)$ & M: $10(5-15)(3 \times$ females $)$ & $n=4(44 \%)$ & M: 10 (9-12) ( $2 \times$ female $)$ \\
\hline Life quality & $n=4(44 \%)$ & $M: 10(9-12)(3 \times$ females $)$ & $n=0$ & \\
\hline
\end{tabular}

${ }^{a}$ Percentage of those interviewed who completed this TM/selected a goal on this TM

All children referenced preferred activities they currently accessed and those they were not accessing, with two children also referencing a regularly accessed activity that they did in fact not enjoy. Two children also highlighted unique activities they enjoyed which were not included in the pre-prepared stimuli but were added to the mat as part of the interview process:

'I love gardening; I go to gardening club at school' (Billy)

'Gardening - well I do it quite a lot but I don't like it at all' (David)

'I like using keyboards and doing the news' (Peter)

When asked if they would like to do more of any activities, four children selected items they would like to increase in the future. This included swimming (two children), games (one child), and music and computers (one child). One child specified a particular aspect of the activity he wanted to do in even more detail:
'Yeah, more swimming. Tomorrow I am going to swimming lesson and I been to leisure centre, that's where I like to go, and at half-term I gone under water two times and I know how to go fast - just lean back' (Max). 'So is it the leisure centre pool, the one with the slide where you want to go to more?' (Researcher). 'Yes.' (Max)

\section{Things You Do}

Eight children completed a TM focused on adaptive aspects of their behavior. Here, all children placed items across different areas of the mat (including the middle column) to indicate personal strengths and needs. For instance, Emily expressed strengths in relation to six areas (including being friendly and polite, looking after herself, and waiting for things), that she was somewhat good in relation to four (sharing, trying new activities, being funny, and asking for help) and not so good at four (including keeping calm, and working hard). All eight children appeared to take pleasure in highlighting their strengths and two children communicated areas they found more difficult and shared something of the struggle they experienced in relation to these: 


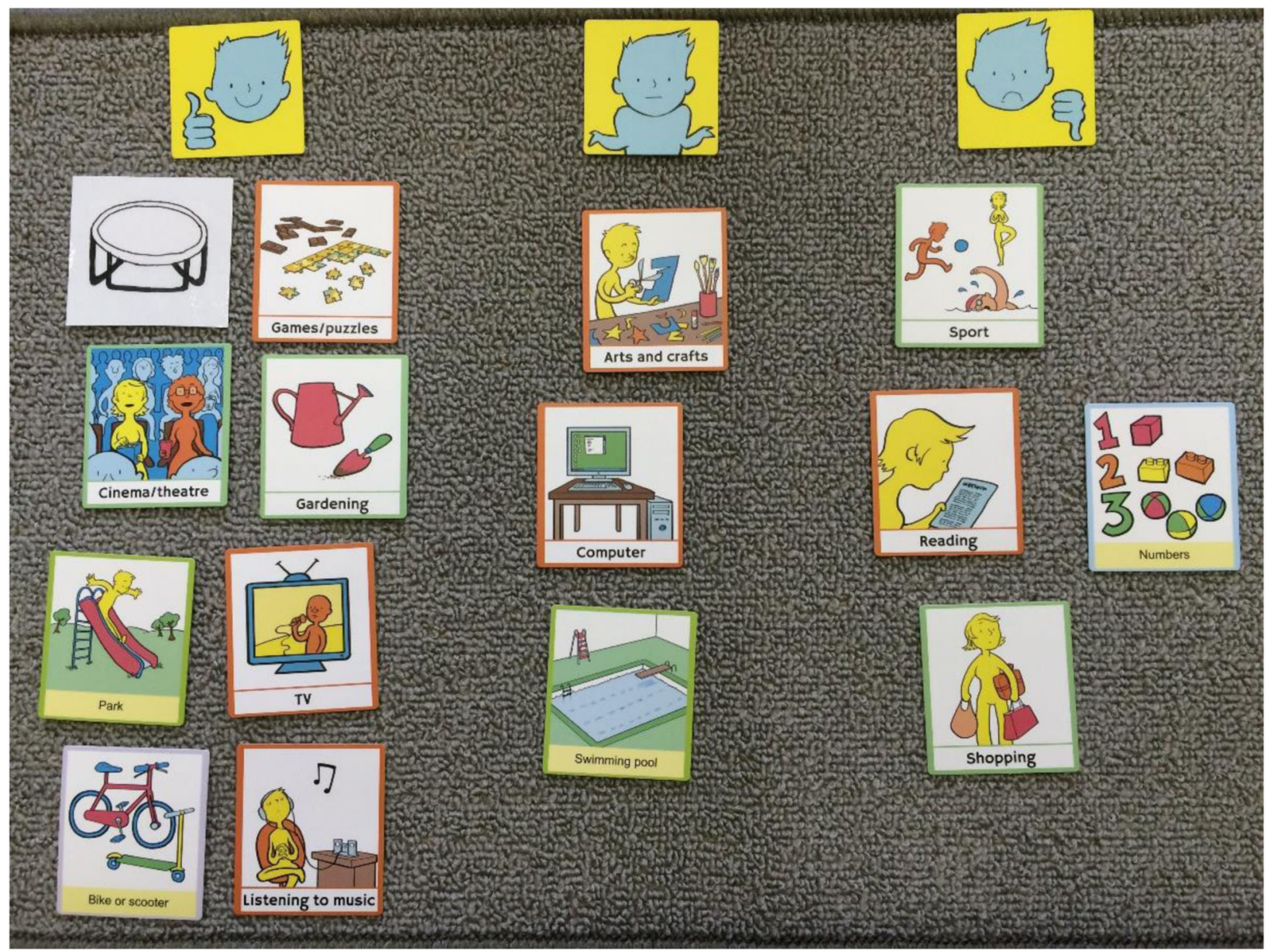

Fig. 1 TM example: "Things you like" (Laura). The Symbols are designed and @ to Adam Murphy 2015 and assigned to Talking Mats Ltd. in perpetuity. They may not be reproduced without permission

'[Helping other people] I do that a lot, like help with my mum's shopping' and 'well Chris has crutches at my school. Got him pencils or a chair' (Natasha)

'Always be a bit hard when see new people and say hello to new people' (Emily)

'I don't like asking for help.' 'I don't like sharing that often.' (Max)

Three children also reflected on the variability of their behavior, discriminated between particular aspects of a given behavior, or recognized that they responded differently dependent on the context. For instance, when presented with an item relating to "asking for help," Natasha indicated she did do this when at school. She was then asked about "asking for help at home" at which point she shook her head. Natasha was then given a second card to symbolize "asking for help at home," which she placed in the right hand column to indicate something she did not do. Two other children communicated further details or distinctions about their behavior verbally and four highlighted one or more area they would like to develop strengths in, or be supported for by others. These related to skills in emotional regulation such as keeping calm or being brave (three children) and/or other social interaction and self-determination skills including asking for help and trying new things, making choices, and waiting (two children):

'Can I put it in the good and bad? Because I'm good at half it and half not' (Peter)

'Well I do like being loving but I don't like being kissed.'(Max) 
'I'm bouncing with fun coz going to see them but this half is not that sure because going somewhere I've not been, well have been but get a bit scared, so that's what' (Emily)

\section{Other Things You Do}

Eight children completed a TM focused on CB. One child (Max) required some initial support to clarify he was being asked to place items in relation to things he did/did not do, rather than things he liked. All other children appeared to understand questions asked during this TM from the outset and openly shared a range of behaviors that they displayed. This included Max, who once clear about the focus of the mat, indicated he often pinched himself, became angry and upset, or displayed a tantrum; never hit himself, pinched or bit others; and engaged in a further six behaviors on some occasions (including screaming, breaking things, and kicking others). Every child reported that they displayed some CB either often or sometimes that included topographies identified by their caregiver at recruitment. Two children indicated behaviors they displayed that had not previously been highlighted by their caregiver. For instance, Emily noted "yes I do, do that" in relation to an image of self-biting (though no forms of selfinjury had previously been indicated by her caregiver):

'I don't like getting angry and upset' (Max). 'Arr yes - I see - but is it ever something you do, even if you don't like it?' (Researcher). 'er......yeah.' (Max)

'Ooh I do that always, pull [sister's] hair if she hurts me.' (Peter)

'Sometimes even tip the sofa when I'm mad' (Ben)

In the context of placing stimuli on the mat, three children referenced an emotional state that accompanied or preceded the behavior, using their own terms to do this, and three commented on the behavior of other people that provided context or motivation for their CB. Finally, in one instance a child (Laura) discussed insight into her selfinjurious behavior indicative of a non-social function:

'Getting cross, sometimes, when some people are naughty to me.' 'Sometimes [brother] is stroppy, he winds me up.' (Billy)

'I do that if I hurt and it stops for a sec, and I give myself a bang, when I got pains' (Laura)
Five children selected goals on this mat to reduce one or more of the behaviors they had highlighted. For Peter, this included finding ways to less often head-bang, bite and scratch himself; for Ben to have fewer 'freak outs'; and for David to kick and shout less. One child identified a goal that also gave some indication of the underlying function this may have served:

'Pulling Daddy's arm, not hurting Daddy, but I don't want him to go' (Laura)

\section{Things Your Parent Does}

Eight children completed a TM focused on parent behavior. Separate mats were completed in relation to positive aspects of parenting and unhelpful aspects on three occasions. Owing to time restrictions, a combination of these stimuli were presented on the same mat on a further three occasions and only positive items were covered in two cases. In all cases, children selected their primary caregiver as the focus for questions and appeared to understand that they were now being asked to think about the behavior of that person as opposed to their own behavior. Children who took part in this phase of the interview identified several positive behaviors they perceived their parent to display. These included joint activities such as drawing, cooking, or playing (seven children); help and assistance (eight children); social interactions like talking, listening, and laughing together (seven children); and giving praise and rewards (four children). All of these children also indicated behaviors of this nature that their caregiver did not display, and in two instances gave further comment or rationale to explain placements they made. For example:

'We do that - helps me having my blood test - holds my hand, squeezes it very tight.' (Emily)

'We don't do much together.' (Ben)

In addition to positive parenting practices, all children presented with relevant stimuli, identified and communicated less positive/unhelpful behavior their caregiver did/ did not display. Items selected by children as displayed often or sometimes by their caregiver included reprimands and shouting (four children); negative punishments such as taking away preferred items or ignoring (four children); restraints or smacking (one child); and arguing in front of children (three children). One child (Billy) also engaged in more detailed discussion of his experience of one of these behaviors: 
'[Shouting] Arr... sometimes. These two should go together like shouting "go to your room."” (David)

'Holding me, like in a bad way? No she never does that.' (Ben)

'I can't get through them. That's Daddy, Mummy argues with Daddy.' (Billy). 'Is that you?' (Researcher). 'Yes trying to get through them.' (Billy)

Children's goals related to altering aspects of caregiver behavior, and were identified by four children. Positive parent behaviors that children wanted to increase comprised favored activities with a caregiver such as playing (three children); cooking or drawing (three children) together with having more praise, rewards (two children) and cuddles (one child). Four children selected behaviors they would like their caregiver to reduce, including: arguing with others (one child); reprimands, smacking, and removal of/restrictions to preferred items and activities (three children):

'[Rewarding and praising you ] definitely that - I'd feel on cloud nine' (Ben)

'Less shouting and smacking. I want those to go whoosh out the door' (David)

\section{Things that are Important}

Four children (three females and one male) completed a TM focusing on life quality domains. In all other cases, we did not present this mat due to time restrictions (three children), or because we believed (from experience in the rest of the interview) that the topic was too complex for the child (two children). One child (Emily) indicated "doing things in the community" was somewhat important (with all other items selected as highly important), and another child (Laura) positioned items across all three columns on the mat. Two children indicated all items presented were highly important with one (Natasha) emphasizing extra-high importance for relationships with friends and family by placing the corresponding card completely off the board to the left-hand side. Two children also provided some account of why an area was so important to them:

'[Physical Health] - Really important if got tummy ache like I've got now since April they always say need to keep healthy, keep fit - and my periods are really bad, makes me feel sad.' (Emily)
'[Personal Development] - When I achieve something I've been working on for a long time that's important.' (Laura)

\section{Discussion}

Prior research interviewing children with IDD (e.g., Aston et al. 2014; Mitchell and Sloper 2001) has not focused on children's own $\mathrm{CB}$, and the small number of attempts to include young people directly in PBS- procedures beyond preference assessments have largely used verbal methods alone and/or focused on those with no/low levels of IDD (Kinch et al. 2001; Murdock et al. 2005; Stage et al. 2006; Wehmeyer et al. 2004). In this study, we developed and explored a process of engaging directly with young people with a range of IDD and a history of CB to identify personal goals and priorities for future support.

\section{Strengths}

We were able to interview nine participants where, as in prior research (Mitchell and Sloper 2001; Small et al. 2013), Talking Mats (TM) was a useful method for approaching complex and sensitive discussions. These children seemed to understand the TM framework and used it with fluency and creativity to express their views and experiences and select goals for support; evidenced by both the variety of placements and accompanying questions and statements. Whilst it was not possible to cover all topic areas with all children, it was noteworthy that no interviews were terminated due to $\mathrm{CB}$. Children overall appeared happy and confident to work with the researcher in the context of proactive supports.

We also created a new coding system and established high inter-rater reliability for coding of participant responses (integrated with a thematic analysis of any verbal responses). In conjunction with a manualised protocol, and use of the EFFC (Murphy and Cameron 2008), this represented a robust methodology. Taken together, the findings of this study suggest, it is possible to directly engage at least some children with IDD and CB as stakeholders in research and in person-centered exercises, with implications for research, practice and policy as will be discussed.

\section{Limitations and Future Research}

Notwithstanding the strengths of this study there were some limitations. Firstly, repeating TMs with children to further examine reliability was not possible in our timeframe, but would allow for further exploration of stability (or contextual variability) in children's responses with the potential to strengthen TM procedures in the future. Similarly, this 
study did not make comparisons to other data or responses obtained from other sources or informants. Related research (i.e., Gore et al. 2019) has explored the use of a similar goal-selection tool with family caregivers and so such considerations could be readily investigated in the future. Here it should however, be recognized that differences in the responses of caregivers and children that may be found are not necessarily indications of poor reliability and may rather reflect differences of opinion or experience.

Secondly, it was not possible to complete interviews with five children, all of whom had limited verbal skills or were non-verbal. A variety of supplementary methods were attempted, but a reliable method of communicating via TMs could not be identified for this latter group. However, the endeavor to engage with children did appear valuable in terms of building rapport and establishing a working relationship with children and families. Developing further methods to support direct involvement in goal formation for children with more severe communication impairments is still needed, and the utility of other augmentative communication approaches (Romski et al. 2015) in this context presents a clear opportunity for future research.

Finally, we did not go on to demonstrate use of goalbased information to develop assessment and PBS interventions, which would form a logical focus for future research. Participants were provided with individual reports detailing their priorities and goals, and it could be reasonably hypothesized that this kind of information could support development of effective interventions, linked to outcomes high in social validity (Dunlap 2006). In line with many person-centered approaches (Carr et al. 2002), we initially asked children to indicate activities they enjoyed and select those they would like to access more in the future. Children's placements and selections were highly individualized and in practice would provide useful information to structure systems of personal support and scheduling of activities (with the life quality domains that were identified by a smaller number of children also being of strategic value in this regard).

\section{Implications}

As a first study focused on direct engagement with children with IDD who displayed CB, the mid-section of interviews that prompted consideration of children's own behavior was of particular interest. Here, children identified both CB and adaptive behaviors they displayed. Children appeared to welcome the opportunity to discuss strengths in adaptive areas, and were open and forthcoming when discussing CB. Byrne and Hennessy (2009) found children with moderate IDD made plausible attributions regarding a peer's CB. Children's comments in the current study also highlighted insights regarding causal and maintaining factors, but in this case with reference to their own behavior. These included actions of other people and reference to emotions that accompanied instances of $\mathrm{CB}$ in children's lived experience. Furthermore, when identifying behaviors they struggled with, some children also specified aspects of $\mathrm{CB}$ or adaptive behavior they would like support to change in the future. Information obtained was rich and personal. Such data would not typically be derived within traditional PBS procedures but would seemingly have great value when developing goals for future assessment and behavior support planning.

Behavior that challenges is known to often occur within a social context, reinforced by the behavior of caregivers (Hastings et al. 2013), and so children were also supported to consider aspects of a caregiver's behavior during interviews. Again, the majority of children interviewed identified and communicated behavior a caregiver did and did not engage in. Behaviors spanned areas that would and would not usually be considered positive/helpful for children's development, and on at least some occasions were selected by children as a goal area for future support. There are few prior examples of individuals who display $\mathrm{CB}$ being invited to comment on the behavior of those who support them, and again this is not a typical aspect of PBS. Studies that have focused on this area (Evans and Gore 2016; Griffith et al. 2013) have typically interviewed adults with IDD through verbal means about their general perspectives on behavior of paid caregivers. Children in the current study were asked about more specific parent behaviors, and given the opportunity to use these as a basis for developing goals. Again, incorporating this novel data source into behavior support planning could have unique potential to bring about change at the level of the caregiver system.

Direct engagement with people who have an IDD reflects the person-centered values of PBS (Lucyshyn et al. 2007; McLaughlin et al. 2012) but also a human rights agenda more generally. For instance, in England, supporting and involving children with IDD in decision-making is recognized in law (Children and Families Act 2014) and is a specific requirement of local authorities as part of the Special Educational Needs and Disability Code of Practice (2015). Self-advocacy and self-directed programs for adults with IDD are also increasingly supported within the United States and UK (DeCarlo et al. 2019; Dew et al. 2019) underpinned by principles of self-determination that are also promoted for youth with disabilities (Deci and Ryan 1985; Wehmeyer et al. 2007). Increasing self-determination and choice-making opportunities for people with disabilities has therefore been called for more broadly in addition to the specific context of CB and PBS (Agran and Brown 2016; Shogren et al. 2004; Turnbull and Turnbull 2000). This study has provided one example of how professionals can actually engage with children in practice to fulfill these recommendations. The study also highlights some of the 
skills and resources required to do this in a meaningful way for individuals who display $\mathrm{CB}$ and whose views are arguably most often missing. Notably, conducting interviews took time and care, working at children's own pace and following discussion and planning with families. Whilst continuing to advocate for the central voice of children and young people, future policy should therefore also recognize and make provision for the complexities of direct engagement procedures.

\section{Conclusion}

In conclusion, this study provides initial evidence of the potential for direct engagement with children/young people with IDD through a structured process to identify priorities and goals for future behavioral support. Future research is required to consider further communication methods that accommodate the needs of an even greater diversity of children and to explore use and elaboration of information and goals derived through procedures of this nature in later stages of assessment and intervention planning. In addition, future research should examine whether outcomes (changes in $\mathrm{CB}$, improved life quality, and increased consumer satisfaction) of PBS interventions are improved as a result of consulting directly with people with IDD.

Acknowledgements This article presents independent research funded by the National Institute for Health Research (NIHR) (DRF-2015-08196). The views expressed are those of the author(s) and not necessarily those of the NHS, the NIHR or the Department of Health.

Author Contributions N.J.G.: conceived the study, led on design, data collection, analysis and writing of paper. P.M.: Supported study design, contributed towards writing and editing of final paper. R.P.H.: Supported study design, contributed towards writing and editing of final paper.

\section{Compliance with Ethical Standards}

Conflict of Interest The authors declare that they have no conflict of interest.

Ethical Approval Ethical approval was granted by London and Harrow Research Ethics Committee (REC ref 16/LO/04546) with Research Sponsorship provided by the University of Kent.

Informed Consent Informed consent was obtained from all individual participants included in this study.

Publisher's note Springer Nature remains neutral with regard to jurisdictional claims in published maps and institutional affiliations.

Open Access This article is licensed under a Creative Commons Attribution 4.0 International License, which permits use, sharing, adaptation, distribution and reproduction in any medium or format, as long as you give appropriate credit to the original author(s) and the source, provide a link to the Creative Commons license, and indicate if changes were made. The images or other third party material in this article are included in the article's Creative Commons license, unless indicated otherwise in a credit line to the material. If material is not included in the article's Creative Commons license and your intended use is not permitted by statutory regulation or exceeds the permitted use, you will need to obtain permission directly from the copyright holder. To view a copy of this license, visit http://creativecommons. org/licenses/by/4.0/.

\section{References}

Agran, M., \& Borwn, F. (2016). Self-determined change: The need for capacity, opportunity and support. Developmental Neurohabilitation, 19(6), 405-409. https://doi.org/10.3109/17518423. 2015.1044134.

Aston, M., Breau, L., \& MacLeod, E. (2014). Understanding the importance of relationships: perspective of children with intellectual disabilities, their parents, and nurses in Canada. Journal of Intellectual Disabilities, 18(3), 221-237. https://doi.org/10.1177/ 1744629514538877.

Baer, D. M., Wolf, M. M., \& Risley, T. (1968). Current dimensions of applied behaviour analysis. Journal of Applied Behaviour Analysis, 1(1), 91-7. https://doi.org/10.1901/jaba.1968.1-91.

Bedoin, D., \& Scelles, R. (2015). Qualitative research interviews of children with communication disorders: methodological implications. European Journal of Special Education, 30(4), 474-489. https://doi.org/10.1080/08856257.2015.1035884.

Boyden, P., Muniz, M., \& Laxton-Kane, M. (2012). Listening to the views of children with disabilities: an evaluation of a learning disability CAMHS service. Journal of Intellectual Disabilities, 17 (1), 51-63. https://doi.org/10.1177/1744629512469923.

Braun, V., \& Clarke, V. (2006). Using thematic analysis in psychology. Qualitative Research in Psychology, 3, 77-101. https://doi. org/10.1191/1478088706qp063oa.

Byrne, A., \& Hennessy, E. (2009). Understanding challenging behavior: perspectives of children and adolescents with a moderate intellectual disability. Journal of Applied Research in Intellectual Disabilities, 22, 317-325. https://doi.org/10.1111/j.1468-3148. 2008.00465.x.

Carr, E. G., Dunlap, G., Horner, R. H., Koegel, R. L., Turnbull, A. P., \& Sailor, W., et al. (2002). Positive behavior support: evolution of an applied science. Journal of Positive Behavior Interventions, 4, 4-16. https://doi.org/10.1177/109830070200400102.

Carr, E. G. (2007). The expanding vision of positive behavior support: research perspectives on happiness, helpfulness, hopefulness. Journal of Positive Behavior Interventions, 9(1), 3-14. https:// doi.org/10.1177/10983007070090010201.

Clarke, S., \& Dunlap, G. (2008). A descriptive analysis of intervention research published in the Journal of Positive Behaviour Interventions: 1999 through 2005. Journal of Positive Behavior Interventions, 10(1), 67-71. https://doi.org/10.1177/ 1098300707311810.

DeCarlo, M. P., Bogenschutz, M. D., Hall-LAnde, J. A., \& Hewitt, A. S. (2019). Implementation of self-directed supports for people with intellectual and developmental disabilities in the United States. Journal of Disability Policy Studies, 3(1), 11-21. https:// doi.org/10.1177/1044207318790061.

Deci, E. L., \& Ryan, R. M. (1985). Intrinsic motivation and selfdetermination in human behaviour. New York, NY: Plenum.

Department for Education. (2014). The Children and Families Act. London: Department for Education.

Department for Education and Department for Health. (2015). Special educational Needs and Disability Code of Practice: 0 to 25 years 
Statutory Guidance for Organisations which Work with and Support Children and Young people who have Special Educational Needs or Disabilities. London: Department for Education.

Dew, A., Collings, S., Dillon, Savage, I., Gentle, E., \& Dowse, L. (2019). "Living the life I want": a framework for planning engagement with people with intellectual disability and complex needs. Journal of Applied Research in Intellectual Disability, 32 (2), 401-412. https://doi.org/10.1111/jar.12538.

Dunlap, G. (2006). The applied behavior analytic heritage of PBS: a dynamic model of action-orientated research. Journal of Positive Behavior Interventions, 8, 58-60. https://doi.org/10.1177/ 10983007060080010701.

Dunlap, G., \& Fox, L. (2007). Parent-professional partnerships: a valuable context for addressing challenging behaviors. International Journal of Disability, Development and Education, 54(3), 273-285. https://doi.org/10.23965/AJEC.42.2.06.

Evans, T., \& Gore, N. J. (2016). Staff behaviors valued by service users: views of people whose behavior challenges. International Journal of Positive Behavioral Support, 6(2), 4-11.

Farrell, A. F., \& Krahn, G. L. (2014). Family life goes on: disability in contemporary families. Family Relations, 63, 1-6. https://doi.org/ $10.1111 /$ fare. 12053 .

Gore, N., et al. (2013). Definition and scope for positive behavioral support. International Journal of Positive Behavioral Support, 3, 14-23.

Gore, N. J., Hastings, R. P., \& Brady, S. R. L. (2014). Early intervention for children with learning disabilities: Making use of what we know. Tizard Learning Disability Review, 19(4), 181-189.

Gore, N. J., McGill, P., \& Hastings, R. P. (2019). Making it meaningful: caregiver goal selection in positive behavioral support. Journal of Child and Family Studies, 28, 1703-1712. https://doi. org/10.1007/s10826-019-01398-5.

Green, C. W., Reid, D. H., White, L. K., Halford, R. C., Brittain, D., \& Gardener, S. M. (1988). Identifying reinforcers for persons with profound handicaps: staff opinion versus systematic assessment of preferences. Journal of Applied Behavior Analysis, 21, 31-43.

Griffith, G. M., Hutchinson, L., \& Hastings, R. P. (2013). "I'm not a patient, I'm a person" the experiences of individuals with intellectual disabilities and challenging behavior: a thematic synthesis of qualitative studies. Clinical Psychology: Science and Practice, 20, 469-488. https://doi.org/10.1111/cpsp.12053.

Hastings, R., Allen, D., Baker, P., Gore, N. J., Hughes, J. C., \& McGill, P., et al. (2013). A conceptual framework for understanding why challenging behaviors occur in people with developmental disabilities. International Journal of Positive Behavioral Support, 3, 5-13.

Horner, R. H., Dunlap, G., \& Koegel, R. L., et al. (1990). Toward a technology of 'nonaversive' behavioral support. Journal of the Association for Persons with Severe Handicaps, 15(3), 125-32. https://doi.org/10.1177/154079699001500301.

Kincaid, D., \& Fox, L. (2002). Person-centred planning and positive behavior support. In S. Holburn \& B. Mount (Eds), Personcentred planning: research, practice and future directions. Baltimore, MD: Paul H. Brookes.

Kincaid, D., Dunlap, G., Kern, L., Lane, K. L., Bambara, L. M., Brown, F., Fox, L., \& Knoster, T. P. (2016). Positive behavior support: a proposal for updating and refining the definition. Journal of Positive Behavior Interventions, 18(2), 69-73. https:// doi.org/10.1177/1098300715604826.

Kincaid, D., Knoster, T., Harrower, J. K., Shannon, P., \& Bustmante, S. (2002). Measuring the impact of positive behavior support. Journal of Positive Behavior Interventions, 4(2), 109-117. https://doi.org/10.1177/109830070200400206.

Kinch, C., Lewis-Palmer, T., Hagan-Burke, S., \& Sugai, G. (2001). A comparison of teacher and student functional behavior assessment interview information from low-risk and high-risk classrooms.
Education and Treatment of Children, 24(4), 480-494. https://www.jstor.org/stable/42900504.

Kruger, B., \& Northway, R. (2019). An exploratory study of behaviour specialist experiences of involving service users in the development of their positive behavioural support plans. Journal of Intellectual Disabilities, 32(2), 160-174. https://doi.org/10.1177/ 1744629517730658.

Lucyshyn, J. M., Albin, R. W., Horner, R. H., Mann, J. C., Mann, J. A., \& Wadsworth, G. (2007). Family implementation of positive behavior support for a child with autism. Journal of Positive Behavior Interventions, 9(3), 131-150. https://doi.org/10.1177/ 10983007070090030201

McClintock, K., Hall, S., \& Oliver, C. (2003). Risk markers associated with challenging behaviours in people with intellectual disabilities: a meta-analytic study. Journal of Intellectual Disability Research, 47(6), 405-16. https://doi.org/10.1046/j.1365-2788. 2003.00517.x.

McLaughlin, T. W., Denney, M. K., Snyder, P. A., \& Welsh, J. L. (2012). Behavior support interventions implemented by families of young children: examination of contextual fit. Journal of Positive Behavior Interventions, 14(2), 87-97. https://doi.org/10. 1177/1098300711411305.

Mitchell, W., \& Sloper, P. (2001). Quality in services for disabled children and their families: what can theory, policy and research on children's and parents' views tell us? Children \& Society, 15, 237-252. https://doi.org/10.1002/chi.658.

Mitchell, W., \& Sloper, P. (2003). Quality indicators: disabled children's and parents' prioritizations and experiences of quality criteria when using different types of support services. British Journal of Social Work, 33, 1063-1080. https://doi.org/10.1093/ bjsw/33.8.1063.

Murdock, S. G., O’Neil, R. E., \& Cunningham, E. (2005). A comparison of results and acceptability of functional behavioral assessment procedures with a group of middle school students with emotional/ behavioral disorders. Journal of Behavioral Education, 14(1), 5-18. https://doi.org/10.1007/s10864-005-0958-z.

Murphy, J., \& Cameron, L. (2008). The effectiveness of Talking Mats with people with intellectual disability. British Journal of Learning Disability, 36, 232-241. https://doi.org/10.1111/j.14683156.2008.00490.x.

Parsons, M. B., \& Reid, D. H. (1990). Assessing food preferences among people with profound mental retardation: providing opportunities to make choices. Journal of Applied Behavior Analysis, 23, 183-195. https://doi.org/10.1901/jaba.1990.23-183.

Preece, D., \& Jordan, R. (2010). Obtaining the views of children and young people with Autism spectrum disorders about their experience of daily life social care support. British Journal of Learning Disabilities, 38, 10-20. https://doi.org/10.1111/j.14683156.2009.00548.x.

Reed, H., Thomas, E., Sprague, J. R., \& Horner, R. H. (1997). The student-guided functional assessment interview: an analysis of student and teacher agreement. Journal of Behavioral Education, 7, 33-49. https://doi.org/10.1023/A:1022837319739.

Romski, M., Sevcik, R. A., Barton-Hulsey, A., \& Whitmore, A. S. (2015). Early intervention and AAC: what a difference 30 years makes. Augmentative and Alternative Communication, 31(3), 181-202.

Shogren, K. A., Fagella-Luby, M. N., Bae, S. J., \& Wehmeyer, M. L. (2004). The effect of choice-making as an intervention for problem behaviour. Journal of Positive Behavior Interventions, 6(4), 228-237. https://doi.org/10.1177/10983007040060040401.

Small, N., Raghavan, R., \& Pawson, N. (2013). An ecological approach to seeking and utilising the views of young people with intellectual disabilities in transition planning. Journal of Intellectual Disabilities, 17(4), 283-300. https://doi.org/10.1177/ 1744629513500779. 
Stage, S. A., Jackson, H. G., Moscovitz, K., Erikson, M. J., Thurman, S. O., Jessee, W., \& Olson, E. M. (2006). Using multimethodmultisource functional behavioral assessment for students with behavioral disabilities. School Psychology Review, 35(3), 451-471. https://doi.org/10.1080/02796015.2006.12087978.

Totsika, V., Hastings, R. P., Emerson, E., Berridge, D. M., \& Lancaster, G. A. (2011a). Behaviour problems at five years of age and maternal mental health in autism and intellectual disability. Journal of Abnormal Child Psychology, 39(8), 1137-47. https:// doi.org/10.1007/s10802-011-9534-2.

Totsika, V., Hastings, R. P., Emerson, E., Lancaster, G. A., \& Berridge, D. M. (2011b). A population-based investigation of behavioural and emotional problems and maternal mental health: associations with autism and intellectual disability. Journal of Child Psychology and Psychiatry, 52(1), 91-9. https://doi.org/10. 1111/j.1469-7610.2010.02295.x.
Turnbull, A., \& Turnbull, R. (2000). Achieving rich lifestyles. Journal of Positive Behavior Support, 2(3), 190-192. https://doi.org/10. 1177/109830070000200310.

Virués-Ortega, J., Pritchard, K., Grant, R. L., North, S., HurtadoParrado, C., \& Lee, M. S. H., et al. (2014). Clinical decisionmaking and preference assessment for individuals with intellectual disabilities. American Journal of Intellectual and Developmental Disabilities, 119(2), 151-170. https://doi.org/10.1352/ 1944-7558-119.2.151.

Wehmeyer, M. L., Agran, M., Hughe, C., Martin, J. E., Mithaug, D. E., \& Palmer, S. B. (2007). Promoting self-determination in students with developmental disabilities. New York, NY: Guilford Press.

Wehmeyer, M. L., Baker, D. J., Blumberg, R., \& Harrison, R. (2004). Self-determination and student involvement in functional assessment. Journal of Positive Behavior Interventions, 6(1), 29-35. https://doi.org/10.1177/10983007040060010501. 